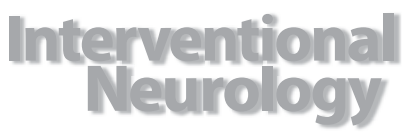

\title{
Novel Distal Emboli Protection Technology: The EmboTrap
}

\author{
Ju-Yu Chueh Miklos G. Marosfoi Olivia W. Brooks Robert M. King \\ Ajit S. Puri Matthew J. Gounis \\ New England Center for Stroke Research, Department of Radiology, University of \\ Massachusetts, Worcester, MA, USA
}

\section{Keywords}

Acute stroke - Embolization - Endovascular stroke therapy · Revascularization · Stroke thrombectomy

\begin{abstract}
Background: Over the course of the thrombectomy procedure, clot fragments may become dislodged and lead to downstream emboli due to manipulation of an endovascular device. The EmboTrap thrombectomy system features an inner stent channel with an outer stent trap design that may potentially reduce the risk of distal clot fragmentation during clot removal. We tested the hypothesis that distal emboli to both the same and new territory generated during mechanical thrombectomy are a function of device design. Methods: EmboTrap and Solitaire thrombectomy were conducted in an in vitro model system that mimicked a middlecerebral artery (MCA) occlusion within a complete circle of Willis vascular replica and a contrast-enhanced clot analog. Emboli generated during the procedure with a size $>1,000 \mu \mathrm{m}$ were collected and measured with calipers. The Coulter principle was used to characterize emboli with a size between 200 and 1,000 $\mu \mathrm{m}$. Results: EmboTrap thrombectomy resulted in a significant reduction in the risk of large emboli $(>1,000 \mu \mathrm{m})$ formation as compared to firstgeneration stent retriever thrombectomy ( $p=0.031$, Fisher exact test). The majority of emboli $>1,000 \mu \mathrm{m}(\sim 80 \%)$ were found in the MCA, regardless of device type. There was no significant difference between the EmboTrap and Solitaire in 200 to 1,000 $\mu \mathrm{m}$ emboli formation $(p=0.89$, Mann-Whitney test). When combining all emboli in the most dangerous range ( $>200$ $\mu \mathrm{m})$, EmboTrap offered a size reduction of emboli $(p=0.022)$. Conclusion: The risk of distal embolization can be altered with improved stent retriever design. When encountering fragment-prone clots, EmboTrap thrombectomy may lower the risk of distal embolization.
\end{abstract}




\section{Introduction}

The findings of recent randomized controlled trials have shown a large benefit from stent retriever-mediated endovascular thrombectomy for selected acute ischemic stroke patients with large-vessel occlusion in the anterior circulation [1-5]. Recanalization rates have improved significantly with stent retriever thrombectomy with meta-analyses of the randomized trials yielding mTICI (modified treatment in cerebral infarction) $2 \mathrm{~b}-3$ reperfusion of 70-80\% and 90-day modified Rankin Scale 0-2 outcomes of 46-54\% [6, 7]. Some of the areas under investigation to further improve outcomes include improving the rates of full TICI 3 perfusion, minimizing the number of thrombectomy passes required to achieve full reperfusion, and reducing the rates of distal and new territory embolization.

Different thrombectomy techniques and different device designs may influence the rate of embolic events. Studies have suggested that protective effects may be achieved using proximal flow control with a balloon guide catheter [8-11]. The ability of the stent retriever to retain the clot in the stent struts during clot retrieval is an important predictor of successful recanalization and may in part be affected by the device design. Loss of interaction between clot and stent retriever when passing the tortuous cerebral arteries can result in partial or failed thrombectomy, which increases the need for multiple passes and additional rescue therapy. Multiple passes may be associated with poorer clinical outcomes due to delay of recanalization [12] or injury to the vessel [13-16].

The Conformité Européenne (CE)-approved EmboTrap ${ }^{\circledR}$ Revascularization Device (Neuravi Ltd., Galway, Ireland) has a dual-layer structure. The outer open structure of the device is designed to engage the clot with minimal maceration and pin it to the inner stentlike channel [17]. The EmboTrap device also features a distal emboli protection zone to catch possible clot fragments generated during mechanical thrombectomy. The objective of this study is the characterization of distal emboli generated during EmboTrap thrombectomy as compared with existing, first-generation stent retriever technology for the treatment of acute ischemic stroke. It is our hypothesis that the efficacy of thrombectomy devices as indicated by the risk of embolic shower may potentially be altered by stent retriever design alone.

\section{Methods}

Creation of Middle-Cerebral Artery Occlusion

Mechanical thrombectomy was performed in a patient-specific circle of Willis model which was connected to a circulation flow loop in preparation for simulation of cerebrovascular occlusion. The circle of Willis model was selected based on data from magnetic resonance angiograms of 20 patients and had a representative internal carotid artery (ICA) siphon in terms of curvature $\left(0.36 \mathrm{~mm}^{-1}\right)$, diameter $(4.21 \mathrm{~mm})$, and length (20.62 $\mathrm{mm}$ ). During the image post-processing, the 3-D reconstruction of the vasculature was modified to rejoin the M2 and A2 divisions, resulting in a single output from each vascular territory. The virtual design was finally transformed into a physical silicone model using a 3-D printing-assisted manufacturing process [18].

The circle of Willis model was connected to a flow loop which contained a peristaltic roller pump used to deliver an oscillatory flow of saline solution and adjustable clamps to allow the tuning of the peripheral resistance [19]. Real-time flow distribution was monitored using flow sensors (Transonic Systems Inc., Ithaca, NY, USA). Pressure transducers (Validyne Engineering, Northridge, CA, USA) recorded the ICA and distal middle-cerebral artery (MCA) pressure. The model was calibrated to maintain physiologically representative flow in each branch of the model.

An inelastic clot model was generated by thrombin-induced clotting of bovine blood (2.5 NIH-U thrombin/mL blood) with addition of barium sulfate $(1 \mathrm{~g} / 10 \mathrm{~mL}$ blood). This type of clot was prone to fragmentation during mechanical thrombectomy and was chosen to mimic the worst-case scenario with respect to clot fragmentation. A segment of clot ( $4 \mathrm{~mm}$ in diameter and $8 \mathrm{~mm}$ in length) was introduced into the ICA and was carried to the MCA bifurcation by the fluid flow. Details regarding the composition and mechanical behavior of the aforementioned clot model are described elsewhere [20]. 
Fig. 1. Frequency of emboli formation of $>1,000 \mu \mathrm{m}$. MCA, middle-cerebral artery; ACA, anterior cerebral artery.

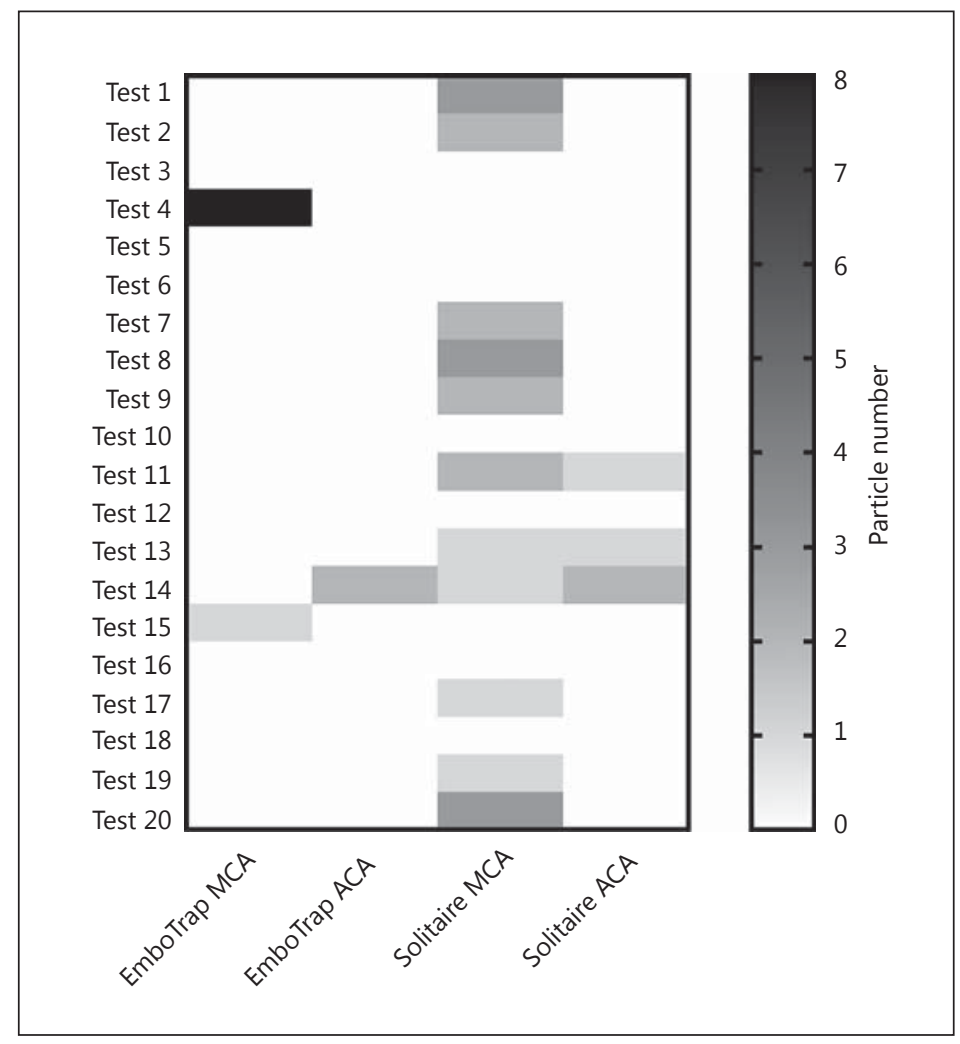

\section{Flow Restoration Procedure}

A Neuron Max 088 guide catheter (Penumbra, Oakland, CA, USA) was placed in the cervical ICA and delivered the 0.014 -inch microwire which was then softly advanced through the clot. A Headway 021 microcatheter (MicroVention, Tustin, CA, USA) was navigated over the wire across the occlusive clot. The microwire was withdrawn followed by device (EmboTrap ${ }^{\circledR}$ or Solitaire ${ }^{\mathrm{TM}}$ FR) deployment for mechanical thrombectomy. The commercially available Solitaire device served as the control device in this study, and active push deployment technique was used to improve the interaction between stent retriever and clot [21]. The device size was $4 \mathrm{~mm} \times 20 \mathrm{~mm}$ for the Solitaire device and $5 \mathrm{~mm} \times 21 \mathrm{~mm}$ for EmboTrap. During retriever retraction, continuous aspiration was applied during retrieval with the assistance of an aspiration pump. Twenty experiments were carried out for each device. The maximum number of thrombectomy attempts was limited to 3 .

\section{Particulate Analysis for Distal Emboli}

Collection of clot fragments started immediately prior to device deployment and ended after clot removal. Clot fragments generated during thrombectomy washed into 2 collection reservoirs, one for emboli to the MCA distribution and the other for emboli to the anterior cerebral artery (ACA) distribution, where they were collected and analyzed. First, clot fragments $>1,000 \mu \mathrm{m}$ were manually separated from the collection chamber and measured with calipers, while those with a size between 200 and 1,000 $\mu$ m were measured with a Coulter counter.

The primary endpoint was the number and size of distal clot fragments generated during the procedure. The secondary endpoint was the rate and number of passes to achieve full flow restoration.

\section{Statistical Analysis}

Statistical analyses were performed with Prism software (GraphPad, San Diego, CA, USA). Results were shown as means \pm standard deviations. The medians of 2 independent groups, if non-normal distributions, were analyzed using the Mann-Whitney test. Categorical comparisons were made using the Fisher exact test. Significance was concluded when $p<0.05$. 


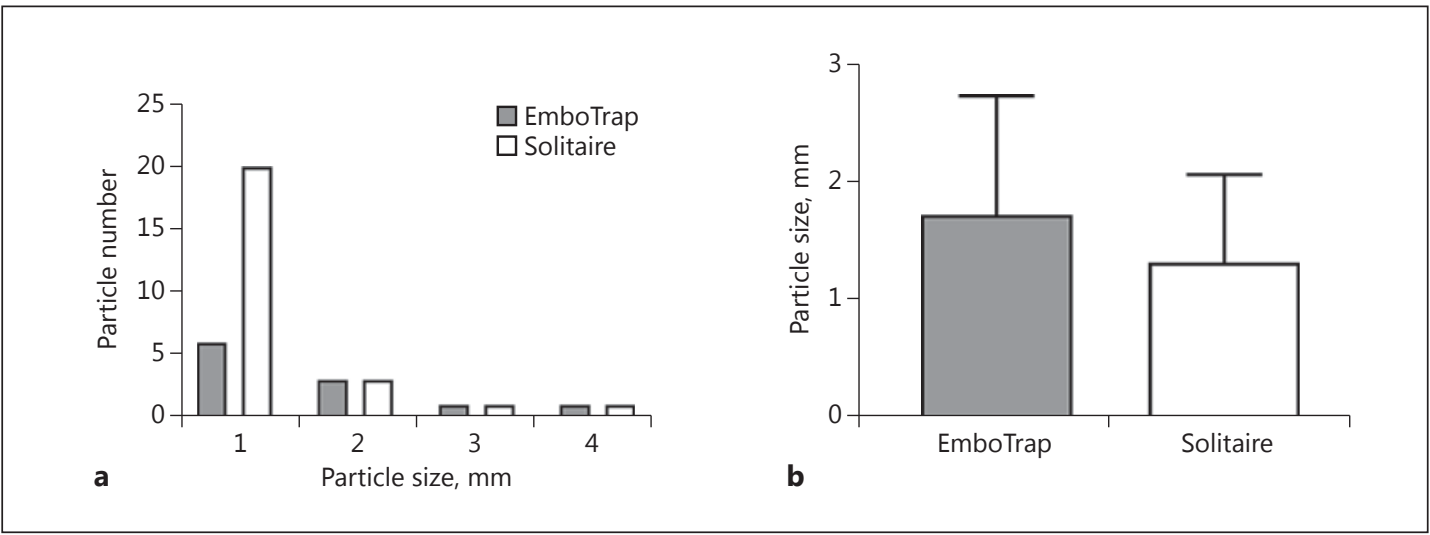

Fig. 2. a Size distribution of clot fragments. The majority of the fragments have a size of $1 \mathrm{~mm}$. b Average size of clot fragments $(>1,000 \mu \mathrm{m})$ produced during mechanical thrombectomy.

\section{Results}

\section{Number of Clot Fragments with a Size $>1,000 \mu \mathrm{m}$}

Formation of clot fragments with a size $>1,000 \mu \mathrm{m}$ was observed in $15 \%$ of cases in the EmboTrap group versus 55\% of cases in the Solitaire control group (Fig. 1). The risk of embolic events in the EmboTrap and Solitaire groups was 10 and 45\%, respectively, when using only first-pass data.

EmboTrap thrombectomy reduced the generation of hard clot fragments with a size $>1,000 \mu \mathrm{m}$ by $>50 \%$, as compared to Solitaire thrombectomy ( $p=0.0096$, Mann-Whitney test). The clot fragments had a size ranging from 1,000 to 4,000 $\mu \mathrm{m}$ (Fig. 2a). There was no significant difference in average clot size between EmboTrap and control groups (EmboTrap: $1,727 \pm 1,009 \mu \mathrm{m}$, Solitaire: 1,320 $\pm 748.3 \mu \mathrm{m}$; Fig. $2 \mathrm{~b}$ ). Importantly, there was a significant reduction in the frequency of large clot fragmentation $(>1,000 \mu \mathrm{m})$ dislodgement $(p=0.031$, Fisher exact test).

\section{Number of Clot Fragments with a Size between 200 and 1,000 $\mu \mathrm{m}$}

There was no significant difference between the EmboTrap and Solitaire devices in clot fragment creation within the 200 to $1,000 \mu \mathrm{m}$ size range ( $p=0.8953$, Mann-Whitney test). A broader size distribution of clot fragments was observed with the Solitaire device (200-770 $\mu \mathrm{m})$ compared to the EmboTrap device (200-325 $\mu \mathrm{m}$ ). Formation of 200 to 1,000 $\mu \mathrm{m}$ clot fragments was observed in $>50 \%$ cases regardless of thrombectomy devices (Fig. 3 ). Excluding those trials where more than one thrombectomy attempt was required, the same results were observed. When combining all particles $>200 \mu \mathrm{m}$, EmboTrap offered a size reduction of clot fragments (545 vs. $650 \mu \mathrm{m}, p=0.0222 ; 314$ vs. $685 \mu \mathrm{m}, p=0.008$ when using only first-pass data).

\section{Distribution of Clot Fragments}

The majority of the disrupted clots with a size $>1,000 \mu \mathrm{m}$ were found in the MCA (approximately $80 \%$ ) in both the EmboTrap and Solitaire groups. On average, 25 and $46 \%$ of the clot fragments with a size between 200 and 1,000 $\mu \mathrm{m}$ travelled through the ACA (unaffected area) with the use of EmboTrap and control devices, respectively. Although the distribution difference did not meet statistical significance ( $p=0.0656$, Fisher exact test), there is a trend of nearly doubling the percentage of emboli that flow to the ACA in the control group. 
Chueh et al.: Novel Distal Emboli Protection Technology: The EmboTrap

Fig. 3. Frequency of emboli formation of 200-1,000 $\mu \mathrm{m}$. MCA, middle-cerebral artery; ACA, anterior cerebral artery.

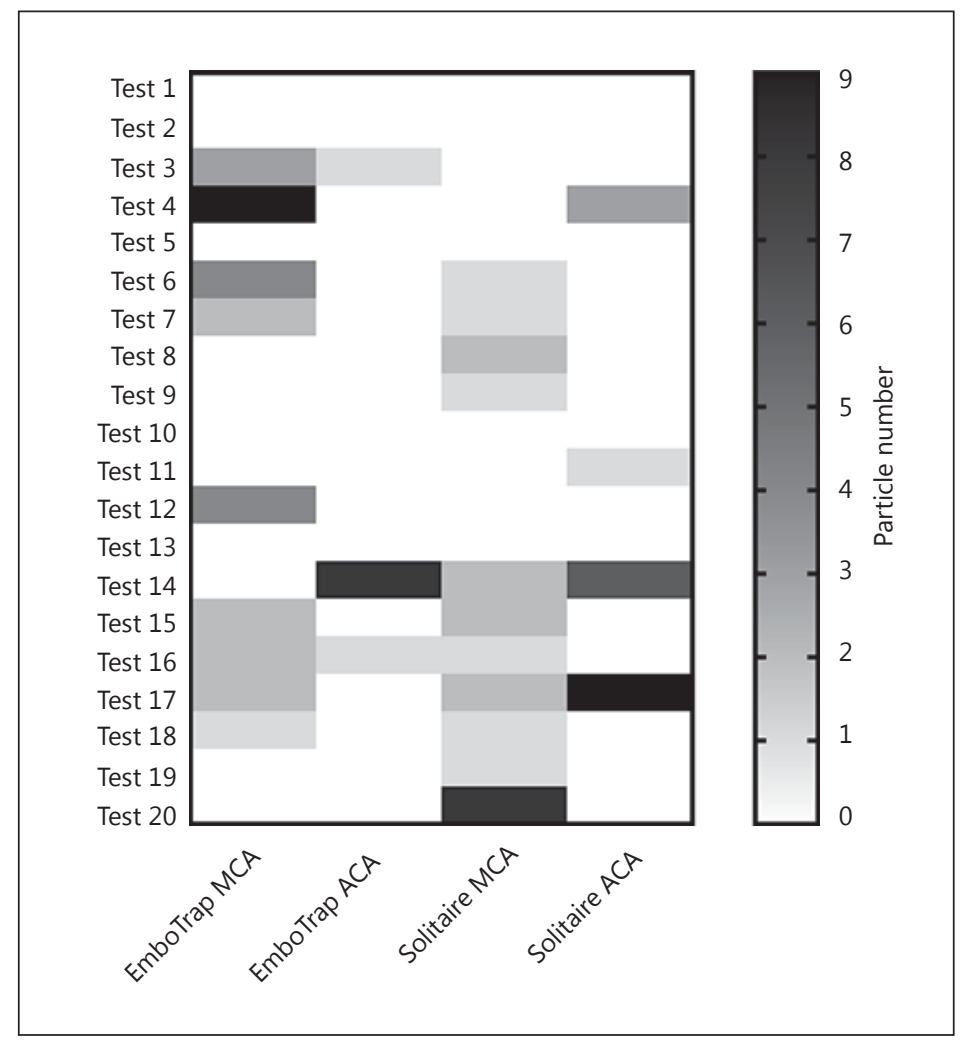

\section{Recanalization Rate and Flow Restoration}

The efficacy of removing the occlusion was very high ( $>90 \%$ first-pass success) in both arms. The EmboTrap devices achieved a 100\% flow restoration in all cases, whereas a $95 \%$ recanalization rate was observed with the control devices. Successful clot removal was achieved at the first attempt in 19 out of 20 cases in the EmboTrap group and in 18 out of 20 cases in the Solitaire group. Although there was no statistical difference in the mean number of pass attempts in the EmboTrap and control groups (1.1 and 1.2, respectively), the number of attempts was, in general, one of the determinants of embolic shower produced during mechanical thrombectomy.

\section{Clot Engagement and Removal through Thrombectomy Devices}

Clot disruption during device retraction was observed to a lesser degree with the EmboTrap device as compared to thrombectomy with Solitaire. Figure 4a-e shows that despite the clot appearing to be integrated with the control device at the beginning of retraction, during passage of each ICA turn (entering the ICA terminus from M1, siphon, and petrosal cervical transition), the clot was progressively disrupted and unstable, thus increasing the potential risk for multiple distal emboli. On the other hand, examples of clot engagement through the EmboTrap stent struts are demonstrated in Figure $4 \mathrm{f}-\mathrm{j}$, which enabled successful clot retrieval. Co-aspiration with a pump was used during this bench test to ensure consistency of aspiration across each thrombectomy run and was helpful in mitigating the embolization risk for fragments forming while entering the receiving catheter. 


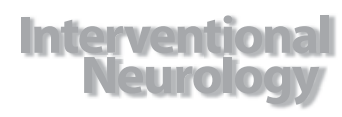

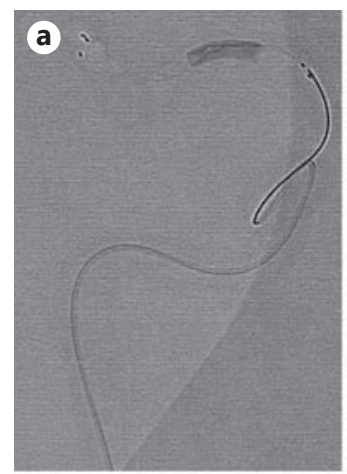
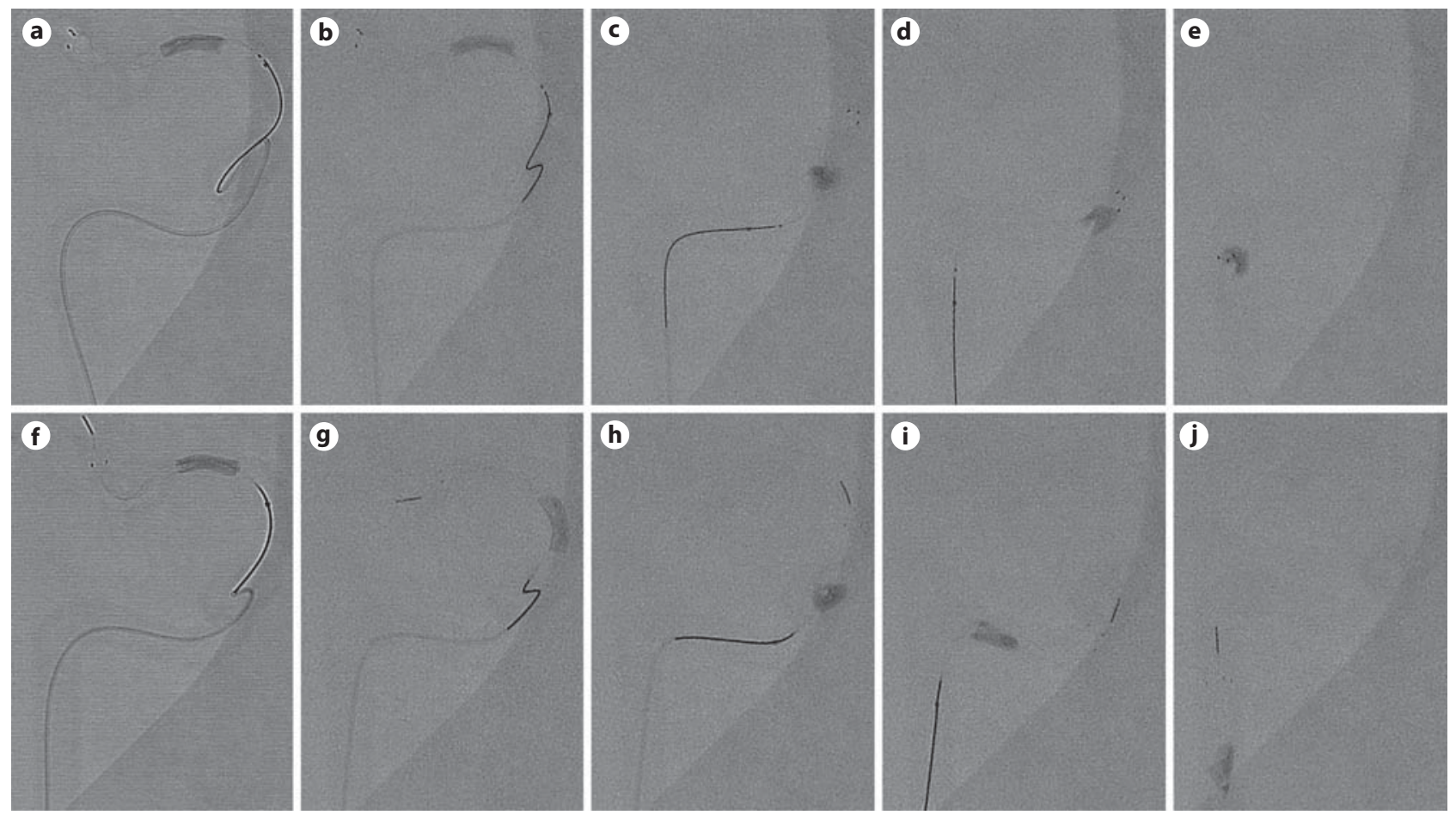

Fig. 4. Still images captured during a single pull of the Solitaire stent (top panels) and of the EmboTrap device (bottom panels) to extract a radiopaque clot. The clot is engaged into the proximal part of the Solitaire stent (a), the pass is initiated (b), and as it navigates through the siphon (c, d), the clot slips along the surface of the device and is only held by the distal end of the Solitaire stent (e). The same procedural steps are illustrated for the EmboTrap device $(\mathbf{f}-\mathbf{j})$, showing clot retention at the same location of the device through all aspects of the thrombectomy.

\section{Discussion}

The efficacy profile of the EmboTrap device was examined in a reproducible experimental setup. The high rate of MCA recanalization observed in this in vitro study is in line with a previous multicenter study in 40 patients [17]. The extent of clot integration into the EmboTrap device was assessed by taking the advantage of the transparent vascular model and radiopaque clot. Furthermore, the open flow loop allowed us to record the risk of distal embolization during EmboTrap thrombectomy in a manner that facilitated comparisons with the gold-standard first-generation stent retriever for clearing large-vessel occlusions.

There have been continuous advances in endovascular techniques for acute ischemic stroke over the past decade, from intra-arterial thrombolysis, Merci Retrievers, and Penumbra aspiration to recent stent retrievers [22, 23]. Compared to the first-generation Merci and Penumbra thrombectomy devices, technical improvements in design of stent retriever-based technology have resulted in higher rates of successful recanalization and improved functional outcome [24, 25].

The EmboTrap is composed of a 2-layer Nitinol structure with a closed tip to facilitate capture of clot debris. Use of the EmboTrap revascularization device was not only associated with a statistically lower number of distal emboli with a size $>1,000 \mu \mathrm{m}$, but also with a less frequent occurrence of embolic events. In addition, when combining all particles $>200 \mu \mathrm{m}$, EmboTrap offered a size reduction of clot fragments. Although only marginally significant, the 
Table 1. Reported clinical rates range from 0 to $12.5 \%$ embolization to new territory

\begin{tabular}{llllr}
\hline Study & $\begin{array}{l}\text { Subjects, } \\
n\end{array}$ & $\begin{array}{l}\text { New territory } \\
\text { embolization }\end{array}$ & $\begin{array}{l}\text { Distal } \\
\text { embolization }\end{array}$ & Ref. \\
\hline Gascou et al., 2014 & 144 & $18(12.5 \%)$ & & 26 \\
Kurre et al., 2013 & 105 & $12(11.4 \%)$ & $55(16.3 \%)$ & 11 \\
NASA, 2013 & 338 & $18(5.3 \%)$ & $15(6.6 \%)$ & 27 \\
Gratz et al., 2014 & 227 & & & 1 \\
MR CLEAN, 2015 & 233 & $20(8.6 \%)$ & $13(22.8 \%)$ & 28 \\
EXTEND-IA, 2015 & 35 & $2(5.7 \%)$ & & 32 \\
Klinger-Gratz et al., 2015 & 57 & & & 32 \\
McTaggart et al. (traditional group), 2016 & 53 & $6(11.3 \%)$ & & \\
McTaggart et al. (CAPTIVE group), 2016 & 39 & $2(5.1 \%)$ & & \\
\hline
\end{tabular}

distribution of disrupted emboli to the ACA territory was almost doubled with Solitaire $(p=$ 0.0656). This likely points to a mechanism where the clot is plowed against the wall by the device and fragments are dislodged into the ACA with the first-generation stent retrievers, whereas the EmboTrap reduces emboli to the ACA by capturing the clot between the inner and outer stent features.

The presence of embolic complications has been associated with poorer outcomes [26, 27]. Reported clinical rates range from 0 to $12.5 \%$ embolization to new territory (Table 1 ). Assessment of distal embolization with angiography can be difficult, and a recent study using susceptibility-weighted imaging indicated that rates may be in the range of $23 \%$ [28]. Susceptibility-weighted imaging seems to be more sensitive to detect emboli than digital subtraction angiography.

In this study, we only characterized clot fragments with a size $>200 \mu \mathrm{m}$. This is due to the limited amount of samples collected during device deployment and retrieval. It should be taken into consideration that the clot fragments generated during the EmboTrap procedure are potentially smaller, since the clot fragments associated with Solitaire thrombectomy could dislodge and further fragment while traveling downstream. Prior quantitative studies have shown the enormous advantage of balloon guide catheter-assisted stent retriever thrombectomy $[29,30]$; however, we chose to use a long sheath, since this is clinically representative and enables testing the hypothesis that stent retriever design alone can alter rates of distal emboli. Subsequent studies should assess adjunctive techniques, such as proximal flow control with and without distal access catheter thromboaspiration.

\section{Conclusions}

Our preliminary data confirm the hypothesis that stent retriever design can be optimized to alter the particle size distribution of distal emboli. When encountering friable hard clots, the use of the EmboTrap device may provide an additional reduction in distal emboli to both affected and unaffected territories.

\section{Acknowledgments}

This study was supported by Neuravi Ltd. The content is solely the responsibility of the authors and does not necessarily represent the official views of Neuravi Ltd. 


\section{Statement of Ethics}

This is an in vitro study. No human or animal subjects were involved in this study.

\section{Disclosure Statement}

Juyu Chueh, Miklos G. Marosfoi, Olivia W. Brooks, Robert M. King, and Ajit S. Puri have no conflicts of interest to declare. Matthew J. Gounis received a research grant and travel support from Neuravi.

\section{References}

1 Berkhemer OA, Fransen PS, Beumer D, van den Berg LA, Lingsma HF, Yoo AJ, Schonewille WJ, Vos JA, Nederkoorn PJ, Wermer MJ, van Walderveen MA, Staals J, Hofmeijer J, van Oostayen JA, Lycklama a Nijeholt GJ, Boiten J, Brouwer PA, Emmer BJ, de Bruijn SF, van Dijk LC, Kappelle LJ, Lo RH, van Dijk EJ, de Vries J, de Kort PL, van Rooij WJ, van den Berg JS, van Hasselt BA, Aerden LA, Dallinga RJ, Visser MC, Bot JC, Vroomen PC, Eshghi O, Schreuder TH, Heijboer RJ, Keizer K, Tielbeek AV, den Hertog HM, Gerrits DG, van den Berg-Vos RM, Karas GB, Steyerberg EW, Flach HZ, Marquering HA, Sprengers ME, Jenniskens SF, Beenen LF, van den Berg R, Koudstaal PJ, van Zwam WH, Roos YB, van der Lugt A, van Oostenbrugge RJ, Majoie CB, Dippel DW; MR CLEAN Investigators: A randomized trial of intraarterial treatment for acute ischemic stroke. N Engl J Med 2015;372: 11-20.

2 Campbell BC, Mitchell PJ, Kleinig TJ, Dewey HM, Churilov L, Yassi N, Yan B, Dowling RJ, Parsons MW, Oxley TJ, Wu TY, Brooks M, Simpson MA, Miteff F, Levi CR, Krause M, Harrington TJ, Faulder KC, Steinfort BS, Priglinger M, Ang T, Scroop R, Barber PA, McGuinness B, Wijeratne T, Phan TG, Chong W, Chandra RV, Bladin CF, Badve M, Rice H, de Villiers L, Ma H, Desmond PM, Donnan GA, Davis SM; EXTEND-IA Investigators: Endovascular therapy for ischemic stroke with perfusion-imaging selection. N Engl J Med 2015;372:1009-1018.

3 Goyal M, Demchuk AM, Menon BK, Eesa M, Rempel JL, Thornton J, Roy D, Jovin TG, Willinsky RA, Sapkota BL, Dowlatshahi D, Frei DF, Kamal NR, Montanera WJ, Poppe AY, Ryckborst KJ, Silver FL, Shuaib A, Tampieri D, Williams D, Bang OY, Baxter BW, Burns PA, Choe H, Heo JH, Holmstedt CA, Jankowitz B, Kelly M, Linares G, Mandzia JL, Shankar J, Sohn SI, Swartz RH, Barber PA, Coutts SB, Smith EE, Morrish WF, Weill A, Subramaniam S, Mitha AP, Wong JH, Lowerison MW, Sajobi TT, Hill MD; ESCAPE Trial Investigators: Randomized assessment of rapid endovascular treatment of ischemic stroke. N Engl J Med 2015;372:1019-1030.

4 Jovin TG, Chamorro A, Cobo E, de Miquel MA, Molina CA, Rovira A, San Roman L, Serena J, Abilleira S, Ribo M, Millan M, Urra X, Cardona P, Lopez-Cancio E, Tomasello A, Castano C, Blasco J, Aja L, Dorado L, Quesada H, Rubiera M, Hernandez-Perez M, Goyal M, Demchuk AM, von Kummer R, Gallofre M, Davalos A; REVASCAT Trial Investigators: Thrombectomy within 8 hours after symptom onset in ischemic stroke. N Engl J Med 2015;372: 2296-2306.

5 Saver JL, Goyal M, Bonafe A, Diener HC, Levy EI, Pereira VM, Albers GW, Cognard C, Cohen DJ, Hacke W, Jansen O, Jovin TG, Mattle HP, Nogueira RG, Siddiqui AH, Yavagal DR, Baxter BW, Devlin TG, Lopes DK, Reddy VK, du Mesnil de Rochemont R, Singer OC, Jahan R; SWIFT PRIME Investigators: Stent-retriever thrombectomy after intravenous t-PA vs. t-PA alone in stroke. N Engl J Med 2015;372:2285-2295.

6 Goyal M, Menon BK, van Zwam WH, Dippel DW, Mitchell PJ, Demchuk AM, Davalos A, Majoie CB, van der Lugt A, de Miquel MA, Donnan GA, Roos YB, Bonafe A, Jahan R, Diener HC, van den Berg LA, Levy EI, Berkhemer OA, Pereira VM, Rempel J, Millan M, Davis SM, Roy D, Thornton J, Roman LS, Ribo M, Beumer D, Stouch B, Brown S, Campbell BC, van Oostenbrugge RJ, Saver JL, Hill MD, Jovin TG; HERMES Collaborators: Endovascular thrombectomy after large-vessel ischaemic stroke: a meta-analysis of individual patient data from five randomised trials. Lancet 2016;387:1723-1731.

7 Campbell BC, Hill MD, Rubiera M, Menon BK, Demchuk A, Donnan GA, Roy D, Thornton J, Dorado L, Bonafe A, Levy EI, Diener HC, Hernandez-Perez M, Pereira VM, Blasco J, Quesada H, Rempel J, Jahan R, Davis SM, Stouch BC, Mitchell PJ, Jovin TG, Saver JL, Goyal M: Safety and efficacy of Solitaire stent thrombectomy: individual patient data meta-analysis of randomized trials. Stroke 2016;47:798-806.

8 Chueh J-Y, Kühn AL, Puri AS, Wilson S, Wakhloo AK, Gounis MJ: Reduction in distal emboli with proximal flow control during mechanical thrombectomy: a quantitative in vitro study. Stroke 2013;44:1396-1401.

9 Menon BK, Sajobi TT, Zhang Y, Rempel JL, Shuaib A, Thornton J, Williams D, Roy D, Poppe AY, Jovin TG, Sapkota B, Baxter BW, Krings T, Silver FL, Frei DF, Fanale C, Tampieri D, Teitelbaum J, Lum C, Dowlatshahi D, Eesa M, Lowerison MW, Kamal NR, Demchuk AM, Hill MD, Goyal M: Analysis of workflow and time to treatment on thrombectomy outcome in the Endovascular Treatment for Small Core and Proximal Occlusion Ischemic Stroke (ESCAPE) randomized, controlled trial. Circulation 2016;133:2279-2286.

10 Velasco A, Buerke B, Stracke CP, Berkemeyer S, Mosimann PJ, Schwindt W, Alcazar P, Cnyrim C, Niederstadt T, Chapot R, Heindel W: Comparison of a balloon guide catheter and a non-balloon guide catheter for mechanical thrombectomy. Radiology 2016;280:169-176. 
11 Nguyen TN, Malisch T, Castonguay AC, Gupta R, Sun CH, Martin CO, Holloway WE, Mueller-Kronast N, English JD, Linfante I, Dabus G, Marden FA, Bozorgchami H, Xavier A, Rai AT, Froehler MT, Badruddin A, Taqi M, Abraham MG, Janardhan V, Shaltoni H, Novakovic R, Yoo AJ, Abou-Chebl A, Chen PR, Britz GW, Kaushal R, Nanda A, Issa MA, Masoud H, Nogueira RG, Norbash AM, Zaidat OO: Balloon guide catheter improves revascularization and clinical outcomes with the Solitaire device: analysis of the North American Solitaire Acute Stroke Registry. Stroke 2013;45:141-145.

12 Saver JL, Goyal M, van der Lugt A, Menon BK, Majoie CB, Dippel DW, Campbell BC, Nogueira RG, Demchuk AM, Tomasello A, Cardona P, Devlin TG, Frei DF, du Mesnil de Rochemont R, Berkhemer OA, Jovin TG, Siddiqui AH, van Zwam WH, Davis SM, Castano C, Sapkota BL, Fransen PS, Molina C, van Oostenbrugge RJ, Chamorro A, Lingsma H, Silver FL, Donnan GA, Shuaib A, Brown S, Stouch B, Mitchell PJ, Davalos A, Roos YB, Hill MD; HERMES Collaborators: Time to treatment with endovascular thrombectomy and outcomes from ischemic stroke: a meta-analysis. JAMA 2016;316:1279-1288.

13 Teng D, Pannell JS, Rennert RC, Li J, Li YS, Wong VW, Chien S, Khalessi AA: Endothelial trauma from mechanical thrombectomy in acute stroke: in vitro live-cell platform with animal validation. Stroke 2015;46:1099-1106.

14 Power S, Matouk C, Casaubon LK, Silver FL, Krings T, Mikulis DJ, Mandell DM: Vessel wall magnetic resonance imaging in acute ischemic stroke: effects of embolism and mechanical thrombectomy on the arterial wall. Stroke 2014;45:2330-2334.

15 Renu A, Laredo C, Lopez-Rueda A, Llull L, Tudela R, San-Roman L, Urra X, Blasco J, Macho J, Oleaga L, Chamorro A, Amaro S: Vessel wall enhancement and blood-cerebrospinal fluid barrier disruption after mechanical thrombectomy in acute ischemic stroke. Stroke 2017;48:651-657.

16 Marosfoi MG, Korin N, Gounis MJ, Uzun O, Vedantham S, Langan ET, Papa AL, Brooks OW, Johnson C, Puri AS, Bhatta D, Kanapathipillai M, Bronstein BR, Chueh JY, Ingber DE, Wakhloo AK: Shear-activated nanoparticle aggregates combined with temporary endovascular bypass to treat large vessel occlusion. Stroke 2015;46: 3507-3513.

17 Kabbasch C, Mpotsaris A, Liebig T, Soderman M, Holtmannspotter M, Cronqvist M, Thornton J, Mendes Pereira V, Andersson T: First-in-man procedural experience with the novel EmboTrap ${ }^{\circledR}$ revascularization device for the treatment of ischemic stroke - a European multicenter series. Clin Neuroradiol 2016;26:221-228.

18 Chueh JY, Wakhloo AK, Gounis MJ: Neurovascular modeling: small-batch manufacturing of silicone vascular replicas. AJNR Am J Neuroradiol 2009;30:1159-1164.

19 Chueh JY, Puri AS, Gounis MJ: An in vitro evaluation of distal emboli following Lazarus Cover-assisted stent retriever thrombectomy. J Neurointerv Surg 2017;9:183-187.

20 Chueh JY, Wakhloo AK, Hendricks GH, Silva CF, Weaver JP, Gounis MJ: Mechanical characterization of thromboemboli in acute ischemic stroke and laboratory embolus analogs. AJNR Am J Neuroradiol 2011;32:1237-1244.

21 Wiesmann M, Brockmann MA, Heringer S, Muller M, Reich A, Nikoubashman O: Active push deployment technique improves stent/vessel-wall interaction in endovascular treatment of acute stroke with stent retrievers. J Neurointerv Surg 2017;9:253-256.

22 Asadi H, Dowling R, Yan B, Wong S, Mitchell P: Advances in endovascular treatment of acute ischaemic stroke. Intern Med J 2015;45:798-805.

23 Pierot L, Soize S, Benaissa A, Wakhloo AK: Techniques for endovascular treatment of acute ischemic stroke: from intra-arterial fibrinolytics to stent-retrievers. Stroke 2015;46:909-914.

24 Nogueira RG, Lutsep HL, Gupta R, Jovin TG, Albers GW, Walker GA, Liebeskind DS, Smith WS; TREVO 2 Trialists: TREVO versus Merci retrievers for thrombectomy revascularisation of large vessel occlusions in acute ischaemic stroke (TREVO 2): a randomised trial. Lancet 2012;380:1231-1240.

25 Saver JL, Jahan R, Levy EI, Jovin TG, Baxter B, Nogueira RG, Clark W, Budzik R, Zaidat O0; SWIFT Trialists: Solitaire flow restoration device versus the Merci Retriever in patients with acute ischaemic stroke (SWIFT): a randomised, parallel-group, non-inferiority trial. Lancet 2012;380:1241-1249.

26 Gascou G, Lobotesis K, Machi P, Maldonado I, Vendrell JF, Riquelme C, Eker O, Mercier G, Mourand I, Arquizan C, Bonafe A, Costalat V: Stent retrievers in acute ischemic stroke: complications and failures during the perioperative period. AJNR Am J Neuroradiol 2014;35:734-740.

27 Gratz PP, Jung S, Schroth G, Gralla J, Mordasini P, Hsieh K, Heldner MR, Mattle HP, Mono ML, Fischer U, Arnold $\mathrm{M}$, Zubler C: Outcome of standard and high-risk patients with acute anterior circulation stroke after stent retriever thrombectomy. Stroke 2014;45:152-158.

28 Klinger-Gratz PP, Schroth G, Gralla J, Jung S, Weisstanner C, Verma RK, Mordasini P, Kellner-Weldon F, Hsieh K, Heldner MR, Fischer U, Arnold M, Mattle HP, El-Koussy M: Protected stent retriever thrombectomy prevents iatrogenic emboli in new vascular territories. Neuroradiology 2015;57:1045-1054.

29 Chueh JY, Kuhn AL, Puri AS, Wilson SD, Wakhloo AK, Gounis MJ: Reduction in distal emboli with proximal flow control during mechanical thrombectomy: a quantitative in vitro study. Stroke 2013;44:1396-1401.

30 Chueh JY, Puri AS, Wakhloo AK, Gounis MJ: Risk of distal embolization with stent retriever thrombectomy and ADAPT. J Neurointerv Surg 2016;8:197-202.

31 Kurre W, Vorlaender K, Aguilar-Perez M, Schmid E, Bazner H, Henkes H: Frequency and relevance of anterior cerebral artery embolism caused by mechanical thrombectomy of middle cerebral artery occlusion. AJNR Am J Neuroradiol 2013;34:1606-1611.

32 McTaggart RA, Tung EL, Yaghi S, Cutting SM, Hemendinger M, Gale HI, Baird GL, Haas RA, Jayaraman MV: Continuous aspiration prior to intracranial vascular embolectomy (CAPTIVE): a technique which improves outcomes. J Neurointerv Surg 2016, Epub ahead of print. 